\title{
Management of Necrotizing Fasciitis: Single centre experience. Retrospective analytical study
}

Mosaad Soliman ( $\nabla$ soliman_mosaad@hotmail.com )

https://orcid.org/0000-0001-7171-8165

\section{Reem Soliman}

Mansoura University

Khalid Mowafy

Mansoura University

Tamer Khafagy

Mansoura University

Nashaat Elsaadany

Mansoura University

Ahmed Elmetwally

Mansoura University Faculty of Medicine https://orcid.org/0000-0003-3735-4841

\section{Research article}

Keywords: Necrotizing fasciitis, soft tissue infections, diabetes mellitus, amputation

Posted Date: May 8th, 2020

DOl: https://doi.org/10.21203/rs.3.rs-25161/v1

License: (c) (i) This work is licensed under a Creative Commons Attribution 4.0 International License.

Read Full License 


\section{Abstract}

\section{Background:}

Necrotizing fasciitis (NF) is a rare soft tissue infection, that is rapid and subtle. Inflammation and necrosis begin at the fascia, then spread to the subcutaneous fat and the muscles, with subsequent necrosis of the overlying skin. Predominantly affecting patients suffering from immune compromise, diabetes mellitus, or vascular insufficiency that prompt early diagnosis and urgent surgery.

\section{Methods:}

A retrospective analytical study conducted at diabetic foot surgery unit, vascular and endovascular surgery department, Mansoura university hospital, including all patients diagnosed with NF, from January 2019 to December 2019. All patient's records were analyzed to determine preexisting illnesses, admitting symptoms including the length of time to access medical care, physical admission findings, laboratory results, site of origin of the initial infection, extent and depth of spread, and microbiology of the wound cultures. The procedure of surgical management described as an aggressive debulking of infected tissue. All necrotic skin, subcutaneous tissue, fascia, and nonviable muscle were removed and sent for microbiologic and histologic examination. Viable dermis and soft tissue were saved to aid following the closure, even after undermining to remove all necrotic fascia.

Study design: Retrospective analytic study

\section{Results:}

A total of 850 patients with diabetic foot were admitted wherein NF diagnosed in 107 patients $(12.6 \%)$. All four types were recorded in different ratios; Type I ( $n=22,20.6 \%)$, Type II ( $n=48,38.3 \%)$, Type III ( $n=30$, $28 \%)$ and Type IV ( $n=14,13.1 \%)$. Age ranged between 9-85 years with mean 48.60 years; gender distribution was 55 female (51.4\%) and 52 males (48.6\%). Diabetes mellitus (49.5\%) was the most common identifiable risk factor while immunosuppression, trauma and postoperative complications, fishbone sting, drug abuse and malignancy represented $11.2 \%, 10.3 \%, 9.3 \%, 8.4 \%$ and $4.7 \%$ respectively. In seven cases (6.5\%), no apparent cause was discovered. 73 cases $(68.2 \%)$ presented with late manifestations such as blisters, purple or blue skin patches $(n=30,28 \%)$ crepitus $((n=17,15.9 \%)$, necrosis ( $(n=20,18.7 \%)$ and multi-organ failure $(n=6,5.6 \%)$. On the other hand; early manifestations in the form of pain out of proportion clinical signs, erythema and tenderness was reported in $31.8 \%(n=34)$. The anatomical sites of NF involved; extremities, trunk and perineum in 80 (74.8\%), 15 (14\%), and 12 patients $(11.2 \%)$ respectively. The total leucocytic count was elevated in nearly all cases ranging from 14 to 40 , and C-reactive protein (CRP) ranged from 38 to 300 . Extensive surgical debridement was done in 87 $(81.3 \%)$ cases, amputations in $17(15.9 \%)$ cases of whom 14 cases were presented with late manifestations and disarticulations were done in 3 (2.8\%) cases. Mortality documented in $34.6 \%$ (37 cases) and was intimately related to the time of intervention, where immediate intervention resulted to a lower mortality rate $13.1 \%(n=14)$ than the early intervention $21.5 \%(n=23)$. Patients with late symptoms 
and signs had higher mortality $(n=27,25.2 \%)$ than cases with early presentation $(n=10,9.4 \%)$ twenty-one patients (50\%) had undergone MRI imaging that was required and led to delay in the surgical exploration.

\section{Conclusion:}

Necrotizing fasciitis is no longer rare but a severe disease that might cause mortality, very early (within 4 hours) surgical management is recommended, especially in cases with late symptoms and signs. Female gender is a significant predictor of mortality. Surgical exposure should be prompt without delay for the results of Magnetic resonant imaging (MRI) once NF is suspected.

Trial Registration: IRB Mansoura university committee approval number R.19.09.605.R1, retrospectively registered 21 September 2019.

\section{Introduction:}

Necrotizing fasciitis (NF) is a rare soft tissue infection that is rapid and subtle onset of spreading inflammation and necrosis beginning at the fascia, then spread to the subcutaneous fat and the muscles, with subsequent necrosis of the overlying skin. Hippocrates (500 BC) gave an early description as "diffused erysipelas caused by trivial accidents, where flesh, sinews, and bones fell away in large quantities, leading to death in many cases" . ${ }^{1}$ The first description of "modern" NF was made by Joseph Jones, during the American Civil war in 1871. Two thousand six hundred forty-two cases of gas gangrene were reported with a mortality rate of more than $46 \%{ }^{2}$ Stevens reported that, among 20 patients who presented with streptococcal shock, were diagnosed as having NF. The media popularized the disease as "flesh-eating bacteria syndrome" 3 . Necrotizing soft tissue infections are commonly affecting patients with underlying immune compromise, diabetes mellitus, or vascular insufficiency. Prompt diagnosis and adequate early debridement can reduce mortality and reduce the rate of amputations from necrotizing soft tissue infections. Its rarity and the scarcity of early diagnostic signs make NF a significant challenge ${ }^{4}$. Once suspected, rapid implementation of treatment, including surgical debridement and broadspectrum antibiotics with intensive care to break the infective process and avoid systemic organ affection, are the sole pathway for successful treatment ${ }^{5-6}$. However, the insidious nature of the disease and the similarity with other simple conditions might lead to a delay in the diagnosis and subsequent treatment. ${ }^{6-7}$. For this reason, mortality rates have remained almost unchanged throughout the centuries. Unfortunately, the lower prevalence of the disease is the leading cause that physicians rarely become sufficiently confident with NF diagnosis and to be able to proceed with rapid management.

\section{Patients and Methods:}

This study is a retrospective analytical study conducted at diabetic foot surgery unit, including all patients diagnosed with NF, over the year 2019. The study was approved by our Institutional Review Board at Mansoura University under number R.19.09.605.R1, retrospectively registered 
All patient's medical records were reviewed and analyzed to determine preexisting illnesses, admitting symptoms (including the length of time to accessing medical care), physical admission findings, laboratory results, site of origin of the necrotizing infection, extent and depth of spread, and microbiology of the initial wound cultures. The diagnosis was confirmed by either histologic examination or a combination of clinical, microbiologic, and gross anatomic findings.

The type and duration of antibiotic therapy, the frequency and type of operative procedures performed and subsequent complications.

Each patient's premorbid medical profile, condition at admission, and subsequent treatment were also analyzed to assess the effect on mortality and development of complications.

Standard treatment after admission, including cardiovascular stabilization, assessment of the extent of the infection, administered antibiotics were collected and analyzed. The datasets during and/or analysed during the current study available from the corresponding author on reasonable request.

\section{The procedure of surgical management}

Aggressive debulking of infected tissue. All necrotic skin, subcutaneous tissue, fascia, and nonviable muscle were removed and sent for microbiologic and histologic examination. Viable dermis and soft tissue were saved to aid following the closure, even after undermining to remove all necrotic fascia.

\section{Statistical analysis}

The data were analyzed using Statistical Package for the Social Sciences. The numerical outcomes, e.g. age, was calculated as mean. Gender was recorded as frequency and percentage. Chi-Square test was applied to assess the association of various parameters. The results were considered statistically significant if the $p$-value is found to be less than or equal to 0.05 . To assess possible risk factors for mortality, univariate analyses was completed initially to aid in determining the variables that should be included in a stepwise logistic regression model.

\section{Results:}

The total number of cases admitted during the period of the study were 850 , wherein NF diagnosed cases with complete medical reports and data, were 107, (12.6\%) patients. We followed the classification of Evangelos P. Misiakos et al. 8 of NF, as demonstrated in (Table 1). According to Culture and sensitivity from wounds of NF patients; Type I $(n=22) 20.6 \%)$ was mainly polymicrobial; distributed in the anterior abdominal wall, gluteal and perineal regions while Type II $(n=48) 38.3 \%)$ was localized in the lower limbs as a monomicrobial infection. Type III $(n=30,28 \%)$ that is attributed to the specific pathogen (Clostridium species, Vibrio cholera or Aeromonas hydrophila); was detected in 20 patients in the lower limbs. Type IV $(n=14,13.1 \%)$ was associated with immunosuppression and caused by rare pathogens (Candida). Mean age of patients was (48.60 years \pm 16.6 ) range, 9 - 85 years. Gender distribution was 55 female $(51.4 \%)$ and 52 male (48.6\%). Fifty-three patients had diabetes (49.5\%), and 7 (6.5\%) did not show any apparent 
cause. Trauma and postoperative complications were the leading cause in 11 cases (10.3\%), drug addiction in 9 cases (8.4\%), immunosuppression in 12 cases (11.2\%), a Fish sting in 10 cases $(9.3 \%)$ and malignancy in 5 cases (4.7\%). Table 2.

Table 1

Classification of responsible pathogens according to the type of infection.

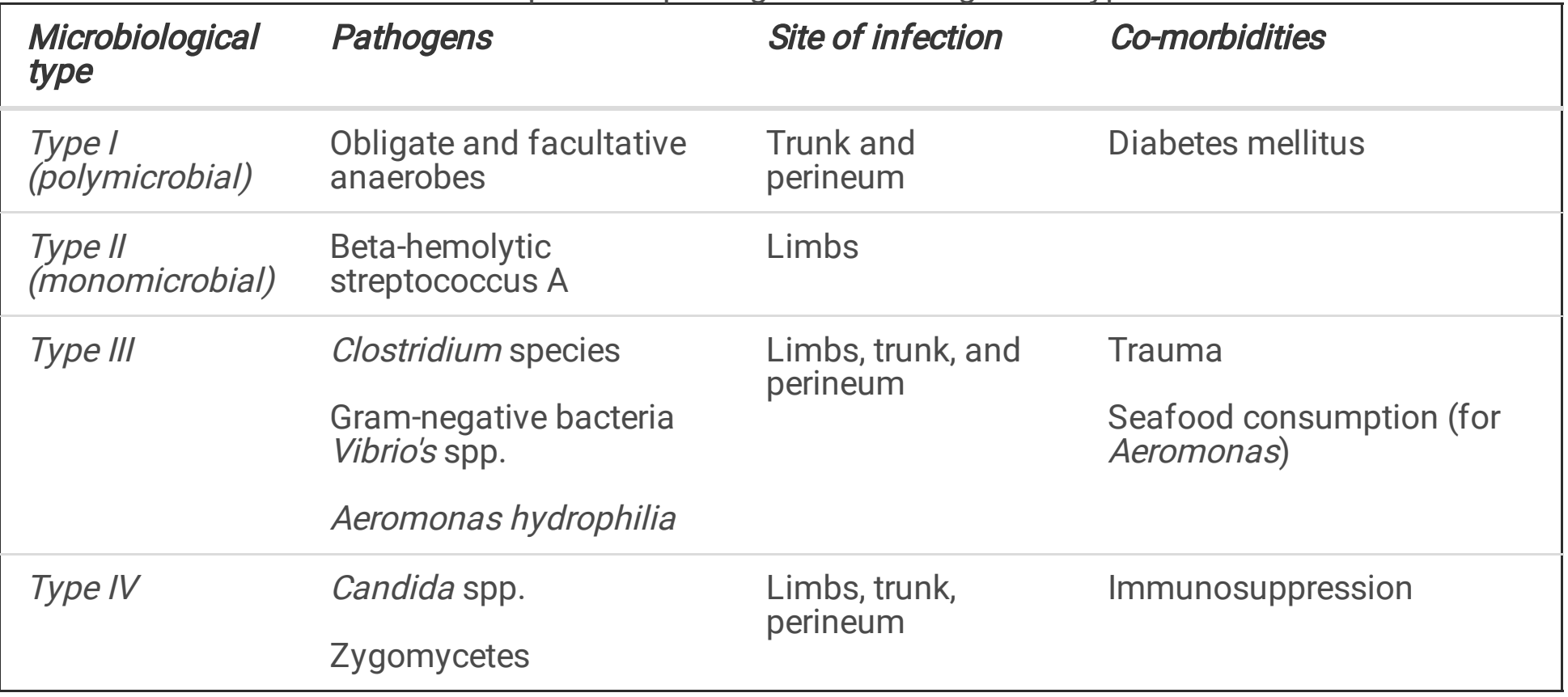




\begin{tabular}{|c|c|c|c|}
\hline \multicolumn{2}{|c|}{ Table 2: Patient's characteristics and Demographics. } & \multirow[t]{2}{*}{ Number } & \multirow{2}{*}{$\begin{array}{l}\text { Percentage } \\
\%\end{array}$} \\
\hline Age & Mean 48.60 (SD 16.6); 9-85 years old & & \\
\hline \multirow[t]{2}{*}{ Sex } & Male & 52 & $48.6 \%$ \\
\hline & Female & 55 & $51.4 \%$ \\
\hline \multirow[t]{7}{*}{ Risk Factors } & No apparent risk factors & 7 & $6.5 \%$ \\
\hline & Malignancy & 5 & $4.7 \%$ \\
\hline & Diabetic Mellitus & 53 & $49.5 \%$ \\
\hline & Drug addict & 9 & $8.4 \%$ \\
\hline & Immune suppression & 12 & $11.2 \%$ \\
\hline & Fish Bites & 10 & $9.3 \%$ \\
\hline & Trauma and post-operative complications & 11 & $10.3 \%$ \\
\hline \multirow[t]{2}{*}{ Clinical Presentation } & Early symptoms and signs & 34 & $31.8 \%$ \\
\hline & Late symptoms and signs & 73 & $68.2 \%$ \\
\hline \multirow[t]{5}{*}{$\begin{array}{l}\text { Clinical } \\
\text { Presentations }\end{array}$} & $\begin{array}{l}\text { Pain out of proportion, Erythema and } \\
\text { Tenderness }\end{array}$ & 34 & $31.8 \%$ \\
\hline & Blisters, Purple or blue skin colour & 30 & $28 \%$ \\
\hline & Crepitus & 17 & $15.9 \%$ \\
\hline & Necrosis & 20 & $18.7 \%$ \\
\hline & Multiorgan Failure & 6 & $5.6 \%$ \\
\hline \multirow[t]{3}{*}{ Management } & Extensive Surgical debridement & 87 & $81.3 \%$ \\
\hline & Amputation of the limb & 17 & $15.9 \%$ \\
\hline & Disarticulation of the limb & 3 & $2.8 \%$ \\
\hline \multirow[t]{5}{*}{ Antibiotic Therapy } & Levofloxacin & 43 & $40.2 \%$ \\
\hline & Gentamicin & 36 & $33.6 \%$ \\
\hline & Cefotaxime & 8 & $7.5 \%$ \\
\hline & Doxycycline & 7 & $6.5 \%$ \\
\hline & Miscellaneous (Imipenem, cefepime, linezolid) & 13 & $12.1 \%$ \\
\hline \multirow[t]{2}{*}{ Outcome } & survivors & 70 & $65.4 \%$ \\
\hline & Non-survivors & 37 & $34.6 \%$ \\
\hline
\end{tabular}




\begin{tabular}{|c|c|c|c|c|}
\hline Table 3: Outcome of NF & & $\begin{array}{l}\text { No } \\
\text { Mortality }\end{array}$ & Mortality & $\begin{array}{l}\mathrm{P}- \\
\text { value }\end{array}$ \\
\hline \multirow[t]{4}{*}{ Types } & Type I & $14(13.1 \%)$ & $8(7.5 \%)$ & \multirow[t]{4}{*}{0.016} \\
\hline & Type II & $30(28 \%)$ & $\begin{array}{l}11 \\
(10.3 \%)\end{array}$ & \\
\hline & Type III & $22(20.1 \%)$ & $8(7.5 \%)$ & \\
\hline & Type IV & $4(3.7 \%)$ & $\begin{array}{l}10 \\
(9.3 \%)\end{array}$ & \\
\hline \multirow[t]{2}{*}{ Clinical Presentation } & $\begin{array}{l}\text { Early symptoms and } \\
\text { signs }\end{array}$ & $24(22.4 \%)$ & $\begin{array}{l}10 \\
(9.4 \%)\end{array}$ & \multirow[t]{2}{*}{0.443} \\
\hline & $\begin{array}{l}\text { Late symptoms and } \\
\text { signs }\end{array}$ & $46(43 \%)$ & $\begin{array}{l}27 \\
(25.2 \%)\end{array}$ & \\
\hline \multirow[t]{3}{*}{$\begin{array}{l}\text { Time of Management since the } \\
\text { admission }\end{array}$} & $\begin{array}{l}\text { Very Early; within } 4 \\
\text { hours }\end{array}$ & $45(42.1 \%)$ & $\begin{array}{l}14 \\
(13.1 \%)\end{array}$ & \multirow[t]{3}{*}{0.001} \\
\hline & Early; within 12 hours & $25(23.4 \%)$ & $\begin{array}{l}23 \\
(21.5 \%)\end{array}$ & \\
\hline & Late; after 12 hours & 0 & 0 & \\
\hline
\end{tabular}

Seventy-three patients (68.2\%) presented with late symptoms and signs such as blisters, purple or blue skin patches $(n=30,28 \%)$, crepitus $(n=17,15.9 \%)$, necrosis $(n=20,18.7 \%)$ and multiorgan failure $(n=6$, $5.6 \%)$. On the other hand; early diagnosis in the form of pain out of proportion, erythema and tenderness was reported in $31.8 \%(n=34)$.

NF documented in 68 patients (63.6\%) in the lower limbs and 15 patients (14\%) in the anterior abdominal wall. On the other hand, 24 cases ( $22.4 \%$ ) were reported equally in upper limbs and gluteal \& perineal regions (12 cases $11.2 \%$ ) (Fig. 2 ).

The elevated total leucocytic count was noticed in nearly all cases ranging from 14 to $40 \times 10^{3} / \mathrm{ml}$ with a mean of $26.77 \pm 7.8 \times 10^{3} / \mathrm{ml}$, and C-reactive protein ranged from 38 up to 300 with a mean of $142.8 \pm$ 70.5. Haemoglobin level $10.4 \pm 2.2$ and serum sodium $134.5 \pm 5.6$, creatinine $1.8 \pm 1.6$ and glucose level $268.6 \pm 127.7$. X-ray was done in all patients, but actual data showing gas formation in the soft tissue was observed in only 41 cases (9 cases with early manifestations and 32 cases with late presentation). Ultrasonography was done in 20 cases to detect nature and extent of infection while MRI with its known high sensitivity was done in 46 cases ( 18 cases with early symptoms and 28 cases with late presentation). Extensive surgical debridement was done in 87 (81.3\%) cases, amputations in 17 (15.9\%) cases ( 14 cases were presented with late symptoms and signs) and disarticulation in 3 cases $(2.8 \%)$. Screening of antibiotics used according to the culture and sensitivity included; Levofloxacin, $(n=43$, $40.2 \%)$ Gentamicin $(n=36,33.6 \%)$, Cefotaxime $(n=8,7.5 \%)$, Doxycycline $(n=7,6.5 \%)$ and miscellaneous (Imipenem,Cefipime and Linozolid) $(n=13,12.1 \%)$. 
Mortality was reported in 37 patients (34.6\%), the immediate intervention; within 4 hours, resulted to a lower mortality rate $13.1 \%(n=14)$ than the early intervention; within 12 hours $21.5 \%(n=23)(p=.001)$. Moreover, late symptoms and signs showed a higher mortality $(25.2 \%(n=27$ cases) than those with early presentation (9.4\% ( $n=10$ cases) $(p=.443)$. MRI imaging was done in more than $50 \%(21)$ patients of the reported mortality and did not improve the outcome but otherwise resulted in a delay in surgical exposure (Table 3).

\section{Discussion:}

At the initial stage of the disease, the diagnosis is difficult in most cases, as documented in the literature. Wilson was the first to create the term necrotizing fasciitis in 1952 when there was rapid progressive necrosis and inflammation of subcutaneous tissue, superficial fascia and superficial part of the deep fascia with the variable presence of cutaneous gangrene. ${ }^{9}$ The annual incidence rate varies in different regions ranging from 0.72 to 9.2 per 100,000 person/year ${ }^{10-11}$ In this study, we report higher incidence rate of $\mathrm{NF}$ than those reported in other countries ${ }^{12} ; 1.63$ in every 100000 people per year in Dakahlia governorate at diabetic foot surgery unit, over a short period of the study where 107 (12.6\%) cases of 850 patients with diabetic foot were recruited.

Although different significant risk factors detailed in the literature such as is trauma, illicit drug use or insect bite, liver cirrhosis, alcoholism, diabetes mellitus, immunosuppression, tuberculosis, chronic kidney diseases and malignancy. However, necrotizing fasciitis can develop without any apparent risk factors. ${ }^{10}$ Diabetes mellitus (49.5\%) was the most common identifiable risk factor while, immunosuppression, trauma and postoperative complications, fish sting, drug abuse and malignancy were reported in $11.2 \%, 10.3 \%, 9.3 \%, 8.4 \%$ and $4.7 \%$ respectively. Meanwhile, 7 cases $(6.5 \%)$ were documented without apparent cause.

Liu TJ et al. observed that age and male gender had a positive correlation with the NF incidence, in our study, age and gender did not reveal any statistical significance as a risk factor, but female gender had an elevated mortality rate; 25 cases $(68 \%)$ than the male. ${ }^{13}$

NF may present by classic manifestations such as soft-tissue oedema (in $75 \%$ of cases), erythema (72\%), severe pain (72\%), tenderness (68\%), fever (60\%), and skin bullae and necrosis (38\%) however the following symptoms and signs are highly suggestive for NF; pain out of proportion to clinical signs, hypotension, skin necrosis, and hemorrhagic bullae. ${ }^{14-15}$ In the present study; we used Evangelos classification ${ }^{8}$ were Type II infections (38.3\%) had been more prevalent followed by type III (28\%) then type I (20.6\%) and finally type IV (13.1\%). These findings were similar to data in other studies where Type II was the commonest in contrary to other reports that experienced a similar incidence of type I and II and the other types vary considerably. ${ }^{16-18}$ Topographically, NF was highest in the extremities $(74.8 \%)$, followed by the trunk (14\%), and lastly the perineum in 12 patients $(11.2 \%)$. This is consistent with the 
results in other studies as wag et al. that declared that necrotizing fasciitis in extremities, trunk and perineum occurred in $74 \%, 13 \%$, and $10 \%$ of patients respectively. ${ }^{19}$

Patients usually present with the collected symptoms as pain, swelling, and fever. Erythema, tenderness, and fever are the commonest signs of early necrotizing fasciitis. In this study, early manifestations in the form of pain out of proportion, erythema and tenderness was reported in 31.8\% ( $n=34)$ wherein 10 cases died (9.4\%) while Seventy-three patients $(68.2 \%)$ presented with late manifestations as blisters, purple or blue skin patches $(n=30,28 \%)$, crepitus $(n=17,15.9 \%)$, necrosis $(n=20,18.7 \%)$ and multiorgan failure ( $n$ $=6,5.6 \%)$; among them 27 cases died (25.2\%). As the mortality was higher in the cases that were manifested with late symptoms and signs, so it is important to recognize necrotizing fasciitis at the early stages in all suspected cases that presented with pain out of proportion of physical examination, even those with minimal cutaneous manifestations. This high index of suspicion of NF must be adopted especially in patients with comorbid conditions such as diabetes mellites or liver diseases as reported at T. Goh et al. ${ }^{4}$

Although the results of laboratory investigations are usually nonspecific, leukocytosis, and increased CRP were the commonest findings in all cases of NF. Highly elevated leucocytic count and CRP is highly specific as discovered by Wong et al. ${ }^{20}$ wherein we found that mean total leukocyte count was $26.77 \pm$ $7.8 \times 10^{3} / \mathrm{ml}$ and CRP ranged $142.8 \pm 70.5$.

The imaging studies such as $\mathrm{x}$-ray was not specific as positive data were showed in 41 cases only where the majority of them were late presentation. However, MRI; done in more than $50 \%(n=21)$ patients, had positive data in all cases especially in that presented early but did not improve the outcome and resulted in a delay in the surgical exposure. The ultrasonography requires highly skilled physician that could be used in the intensive care unit (ICU). However, the finger test; a 2-cm incision is made down to the deep fascia, at which level gentle probing of the index finger is applied, had not been used in this study as a bedside test but during the surgical debridement where the mainstay for investigation and treatment is the Surgical exploration. The NF findings were characteristic "dishwater pus," along with no bleeding or tissue resistance. ${ }^{21-23}$

The conservative treatment of NF through antibiotics alone has a minor role. However, they may have significant value with the surgical management of the infection, and broad-spectrum antibiotics must be started immediately if NF is suspected; based on the microbiological classification of NF. Type 1 infection, which is mainly caused by anaerobic bacteria, should be covered with; metronidazole, clindamycin, or carbapenems (imipenem) are effective antimicrobials. Type 2 infection is mainly caused by S. pyogenes and S. aureus. Ans should be covered with Vancomycin or daptomycin and linezolid in cases where $\mathrm{S}$. aureus is not responding to Vancomycin. Type $3 \mathrm{NF}$, which is caused by Clostridium species, could be treated with clindamycin and penicillin. The early use of tetracyclines (including doxycycline and minocycline) and third-generation cephalosporins is of value for the patient with Vibrio infection is suspected. Type 4 NF should be managed with fluoroconazole or amphotericin B. In this study, we depend mainly on the extensive surgical debridement or take the target off. However, we started 
triple broad-spectrum antibiotics the dosage should be adjusted, based on the results of the initial blood, wound, and tissue cultures, but continued until the infection is under control and for at least $72 \mathrm{~h}$ after the patient stabilized clinically and hemodynamically. ${ }^{24-26}$

The high mortality rate reported in different studies (19-45\%) 4 as well as this study (34.6\%). But the lower mortality achieved with the immediate intervention; within 4 hours, $13.1 \%(n=14)$ than the early intervention; within 12 hours $21.5 \%(n=23)(p=.001)$ so early diagnosis and immediate radical surgical debridement are a must. Surgery is processed if NF is suspected clinically and not be delayed by diagnostics in order to decrease the mortality rate as Leiblein M declared 27

\section{Conclusion:}

Necrotizing fasciitis is no longer rare but a severe disease that might cause mortality, very early (within 4 hours) surgical management is recommended, especially in cases with late symptoms and signs. Female gender is a significant predictor of mortality. Surgical exposure should be prompt without delay for the results of MRI once NF is suspected.

\section{Abbreviations}

\begin{tabular}{|ll|}
\hline NF & Necrotizing Fasciitis \\
\hline MRI & Magnetic resonant imaging \\
\hline CRP & C-reactive protein \\
ICU & intensive care unit \\
\hline
\end{tabular}

\section{Declarations}

\section{Competing interests:}

The authors declare that they have no competing interests

\section{Authors' contributions}

$M S^{*}$, Principle Author, Design of the work, interpretation of data and revised the manuscript, Approved the submitted version, agreed both to be personally accountable for the author's own contributions and to ensure that questions related to the accuracy or integrity of any part of the work, even ones in which the author was not personally involved, are appropriately investigated, resolved, and the resolution documented in the literature.

$A E^{*}$, acquisition, analysis, interpretation of data and drafted the work, revised the manuscript, Approved the submitted version, agreed both to be personally accountable for the author's own contributions and to ensure that questions related to the accuracy or integrity of any part of the work, even ones in which the 
author was not personally involved, are appropriately investigated, resolved, and the resolution documented in the literature.

$R S^{*}$, acquisition, analysis, interpretation of data and drafted the work, revised the manuscript, Approved the submitted version, agreed both to be personally accountable for the author's own contributions and to ensure that questions related to the accuracy or integrity of any part of the work, even ones in which the author was not personally involved, are appropriately investigated, resolved, and the resolution documented in the literature.

$K M^{*}$, professor of vascular surgery acquisition, analysis, interpretation of data and revised the manuscript, Approved the submitted version, agreed both to be personally accountable for the author's own contributions and to ensure that questions related to the accuracy or integrity of any part of the work, even ones in which the author was not personally involved, are appropriately investigated, resolved, and the resolution documented in the literature.

$T K^{\star}$, acquisition, analysis, interpretation of data and revised the manuscript, Approved the submitted version, agreed both to be personally accountable for the author's own contributions and to ensure that questions related to the accuracy or integrity of any part of the work, even ones in which the author was not personally involved, are appropriately investigated, resolved, and the resolution documented in the literature.

NE. *, acquisition, analysis, interpretation of data and drafted the work, revised the manuscript, Approved the submitted version, agreed both to be personally accountable for the author's own contributions and to ensure that questions related to the accuracy or integrity of any part of the work, even ones in which the author was not personally involved, are appropriately investigated, resolved, and the resolution documented in the literature.

\section{Ethics approval and consent to participate}

The study was approved by our Institutional Review Board at Mansoura University under number R.19.09.605.R1, retrospectively registered. The consent was obtained at the time of surgery, both verbally and written, and all consent forms were revised and accepted by the approving committee mentioned above.

\section{Consent for Publication}

All included patient's images were obtained and published after getting the approval of the patient in writing, and also the ethics committee approving the study.

\section{Availability of supporting data}

All data involved in the study are available for review if requested, depending on a suitable request to the corresponding author. 
Funding: Not applicable.

Competing interests: The authors declare that they have no competing interests.

Acknowledgements: Not applicable.

\section{References}

1. Dixon B. Fasciitis continues to surprise. Lancet Infect Dis. 2008;8:79.

2. Jones J. Surgical Memoirs of the War of the Rebellion: Investigation Upon the Nature, Causes and Treatment of Hospital Gangrene as Prevailed in the Confederate Armies 1861-1865. New York, NY: US Sanitary Commission (1871).

3. Stevens DL, Tanner MH, Winship J. Severe group A streptococcal infections associated with a toxic shock-like syndrome and scarlet fever toxin A. N Engl J Med. 1989;321:1-7.

4. Goh T, Goh LG, Ang CH, Wong CH. Early diagnosis of necrotizing fasciitis. Br J Surg. 2014 Jan;101(1):e119-25. Epub 2013 Nov 29.

5. Childers BJ, Potyondy LD, Nachreiner R, et al. Necrotizing fasciitis: afourteen-year retrospective study of 163 consecutive patients. Am Surg. 2002;68:109-16.

6. Astorino T, Genrich I, Macgregor L, Victor CS, Eckhouse DR. BarbourL. Necrotizing fasciitis: early detection may save your patient's limb. Orthop Nurs. 2009;28:70-6.

7. Callahan TE, Schecter WP, Horn JK. Necrotizing soft tissue infectionmasquerading as cutaneous abscess following illicit drug injection. Arch Surg. 1998;133:812-7. discussion 817-819.

8. Misiakos EP, Bagias G, Patapis P, et al Current concepts in the management of necrotizing fasciitis Front Surg. 2014 Sep 29;1:36.

9. Alayed KA, Tan C, Daneman N. Red flags for necrotizing fasciitis: a case control study. Int J Infect Dis. 2015;36:15-20.

10. Tunovic E, Gawaziuk J, Bzura T, Embil J, Esmail A, Logsetty S. Necrotizing fasciitis: a six-year experience. J Burn Care Res: Off Public Am Burn Assoc. 2012;33:93e100.

11. Mulla ZD, Gibbs SG, Aronoff DM. Correlates of length of stay, cost of care, and mortality among patients hospitalized for necrotizing fasciitis. Epidemiol Infect. 2007;135:868e76.

12. Fernando SM, Tran A, Cheng W, Rochwerg B, Kyeremanteng K, Seely AJE, Inaba K, Perry JJ. Necrotizing Soft Tissue Infection: Diagnostic Accuracy of Physical Examination, Imaging, and LRINEC Score: A Systematic Review and Meta-Analysis. Ann Surg. 2019 Jan;269(1):58-65.

13. Liu TJ, Tai HC, Chien KL, Cheng NC." Predisposing factors of necrotizing fasciitis with comparison to cellulitis in Taiwan: A nationwide population-based case-control study." J Formos Med Assoc. 2019 Feb 6. pii: S0929-6646(18)30620-X.

14. Wong $\mathrm{CH}$, Chang HC, Pasupathy S, Khin LW, Tan JL, Low CO. Necrotizing fasciitis: clinical presentation, microbiology, and determinants of mortality. J Bone Joint Surg Am. 2003;85-A:145460. 
15. Devaney B, Frawley G, Frawley L, Pilcher DV. Necrotizing soft tissue infections: the effect of hyperbaric oxygen on mortality. Anaesth Intensive Care. 2015;43:685-92.

16. Jabbour G, El-Menyar A, Peralta R, et al. Pattern and predictors of mortality in necrotizing fasciitis patients in a single tertiary hospital. World J Emerg Surg. 2016;11:40.

17. Nordqvist $G$, Walldén $A$, Brorson $H$, Tham J. Ten years of treating necrotizing fasciitis. Infect Dis (Lond). 2015;47:319-25.

18. van Stigt SF, de Vries J, Bijker JB, et al. review of 58 patients with necrotizing fasciitis in the Netherlands. World J Emerg Surg. 2016;11:21.

19. Wang JM, Lim HK. "Necrotizing fasciitis: eight-year experience and literature review" Braz J Infect Dis. 2014 Mar-Apr;18(2):137-43.

20. Wong C, Khin L. Clinical relevance of the LRINEC (laboratory risk indicator for necrotizing fasciitis) score for assessment of early necrotizing fasciitis. Crit Care Med (2005) 33 :

1677.10.1097/01.CCM.0000170199. 43624.B8.

21. Nagano $\mathrm{N}$, Isomine $\mathrm{S}$, Kato $\mathrm{H}$, Sasaki $\mathrm{Y}$, et al Human fulminant gas gangrene caused by Clostridium chauvoei. J Clin Microbiol (2008) 46:1545-7.10.1128/JCM.01895-07.

22. Marron CD. Superficial sepsis, cutaneous abscess and necrotizing fasciitis. In: Brooks A, Mahoney PF, Cotton BA, Tai N, editors., editors. Emergency Surgery. Oxford: Blackwell Publishing; 2010. pp. 115-23.

23. Monneuse O, Gruner L, Barth X, Malick P, et al Gas gangrene of the abdominal wall due to underlying GI pathology: seven cases. J Chir (Paris) (2007) 144:307-12.10.1016/S0021-7697(07)91959-6.

24. Zimbelman J, Palmer A, Todd J. Improved outcome of clindamycin com-pared with beta-lactam antibiotic treatment for invasive Streptococcus pyogenes infection. Pediatr Infect Dis J. 1999;18:1096.

25. Mulla ZD. Treatment options in the management of necrotizing fasciitis caused by group $A$ Streptococcus. Expert Opin Pharmacother. 2004;5:1695-700.

26. Naqvi GA, Malik SA, Jan W. Necrotizing fasciitis of the lower extremity: a case report and current concept of diagnoses and management. Scan J Trauma Resusc Emerg Med. 2009;17:28.

27. Leiblein M, Marzi I, Sander AL, Barker JH, et al. Necrotizing fasciitis: treatment concepts and clinical results. Eur J Trauma Emerg Surg. 2018 Apr;44(2):279-90.

\section{Figures}




\section{Total of 850 patients admitted over 12 moths}
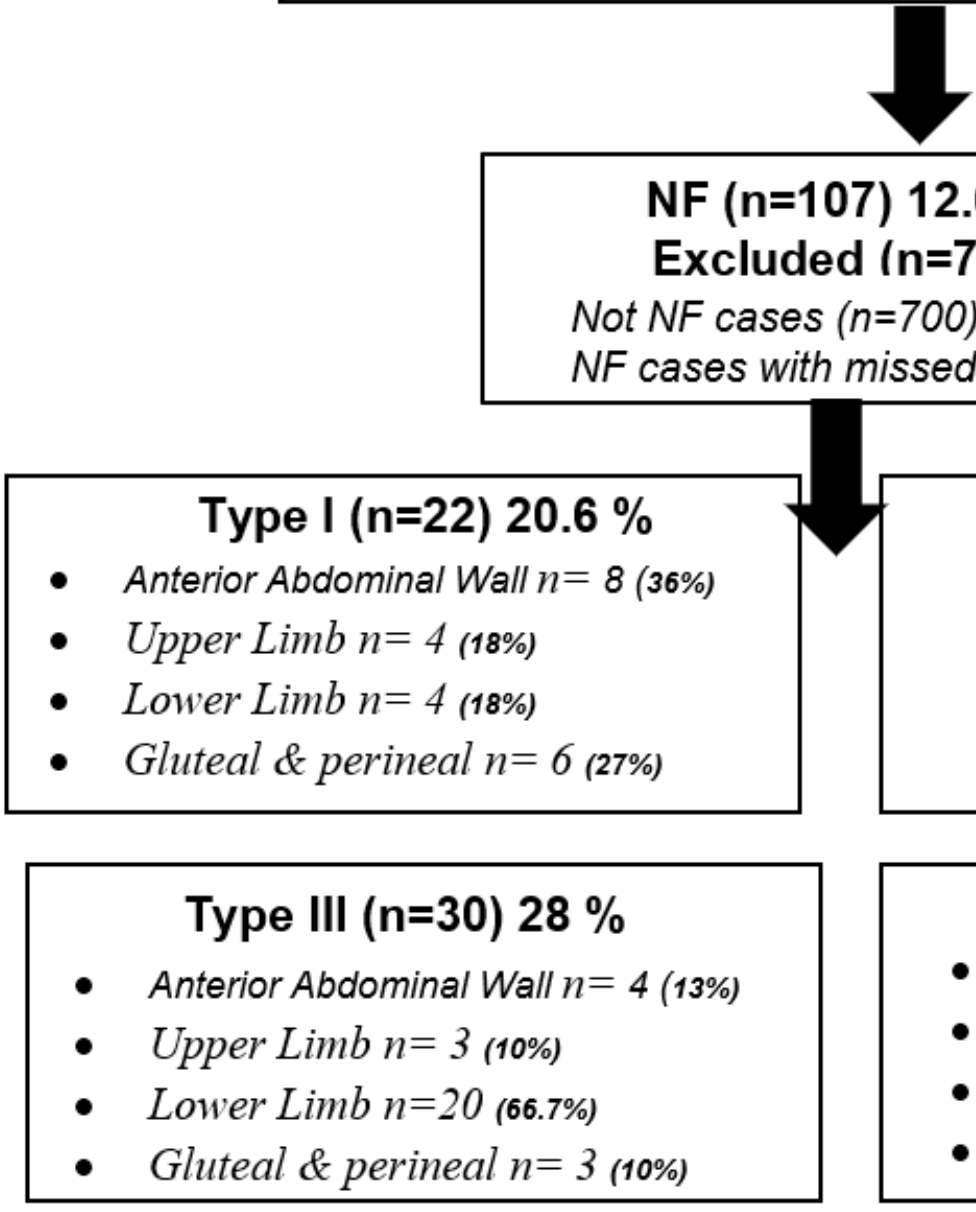

Type II (n=41) $\mathbf{3 8 . 3} \%$

- Anterior Abdominal Wall $n=0$ (0\%)

- Upper Limb $n=4$ (9.8\%)

- Lower Limb $n=37$ (90.2\%)

- $\quad$ Gluteal \& perineal $n=0$ (0\%)

\section{Type IV (n=14) $13.1 \%$}

- Anterior Abdominal Wall $n=3$ (21.4\%)

- Upper Limb $n=1$ (7.1\%)

- Lower Limb $n=7$ (50\%)

- $\quad$ Gluteal \& perineal $n=3$ (21.4\%)

Figure 1

Summary of the study 


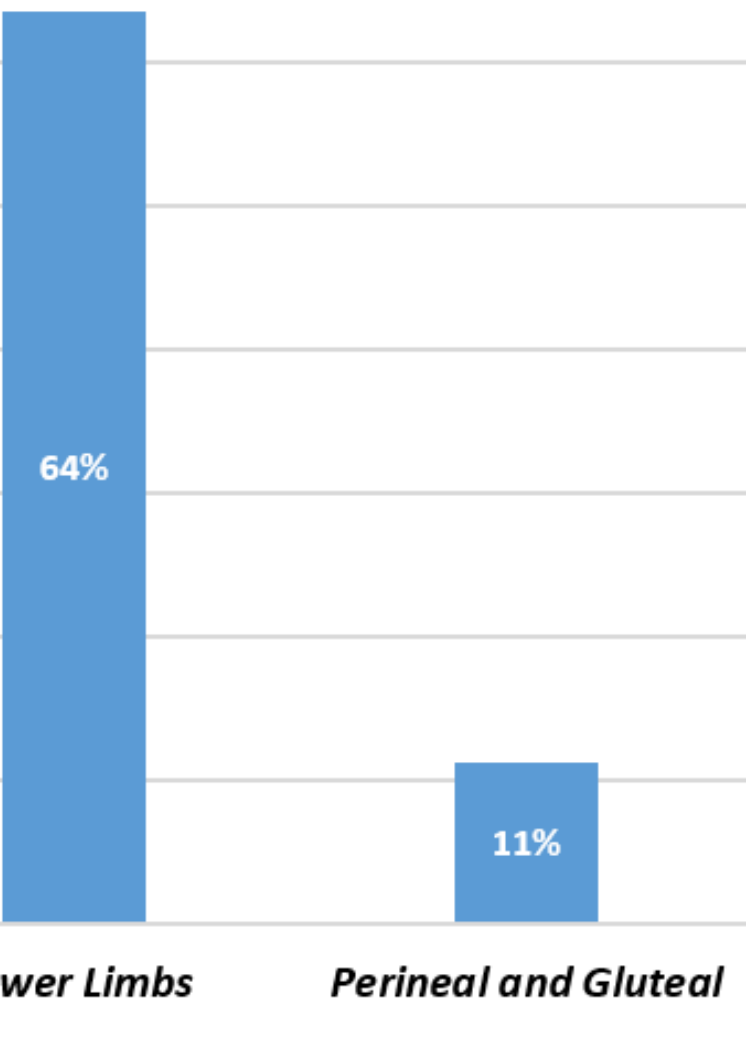

Figure 2

Anatomical site Distributions

\section{Supplementary Files}

This is a list of supplementary files associated with this preprint. Click to download.

- 2.png

- 5.png

- 4.png

- 3.png

- 1.png 